\title{
Miniaturized Triple Seven Shaped Microstrip Patch Antenna for X Band Satellite Communications
}

\author{
V. Keral Shalini, M. Annakamatchi and S. Arthireena \\ Electronics and Communication Engineering, M. Kumarasamy College of Engineering, Karur -639113, \\ Tamil Nadu, India; shalini.keral14@gmail.com, annakamatchiece@gmail.com, arthi.reena@gmail.com
}

\begin{abstract}
Objective: In digital world, the X band or Super High Frequency is widely used by military forces in Satellite Communication for beyond line of sight communications. $\mathrm{X}$ band is most preferable band for military users as antenna able to operate at frequency bands which is suitable for military user's needs. Methods/Statistical Analysis: A Compact triple seven shaped microstrip patch antenna is considered. By employing two rectangular slots that can change the conventional rectangular slot into seven shaped patch, the antenna able to operate in single band in the $\mathrm{X}$ band satellite communication. However, in order to meet military radio spectrum the frequency range is specified at 8 to $12 \mathrm{GHz}$ and wavelength range is about 3.75 to $2.5 \mathrm{~cm}$. Findings: The proposed antenna consists of Rogers RT/duriod 5880 substrate material with the dimension of $50 \mathrm{~mm} \times 50 \mathrm{~mm}$ and triple seven shaped radiating patch with microstrip feed line having the length and width of $0.8 \mathrm{~mm}$ X $5 \mathrm{~mm}$. The compact triple seven shaped microstrip patch antenna resonates at the frequency of $11.4 \mathrm{GHz}$ with $-29.03 \mathrm{~dB}$ return loss. The proposed antenna gain is $2.24 \mathrm{dBi}$. The simulated results show that the proposed antenna operates with stable gain, good return loss, VSWR and consistent radiation efficiency. The good agreement is achieved and it is more suitable for X band applications. Application/Improvements: The applications of the X band are Radar communication, satellite Communication, wireless computer networks and military forces.
\end{abstract}

Keywords: Entangled States, Separable States, Quantum Channels, Quantum Teleportation

\section{Introduction}

UWB antenna for X band applications have created much attention in recent years. Many ultra wide band antennas ranging from $3.1 \mathrm{GHz}-10.6 \mathrm{GHz}$ have been developed for $\mathrm{X}$ band applications. Plenty of antennas have been designed and tested experimentally and numerically to avoid the interference between ultra wide band and narrow band antennas. Radar engineering and military satellite communications require miniaturized, attenuation less and affordable antennas for best communications among themselves. The researchers invested their efforts to design ultra wide band micro strip patch antenna to have $\mathrm{X}$ band military satellite communications. It plays a vital role and usually such type of microstrip antennas have been designed with different substrate materials with different patch shapes based on the frequency which is suited for the various fields in the wireless networks and communications.
The different types of multi band antennas or wide band antennas have been developed to fulfil the demands in modern wireless communication. Many scientists have committed their research works to make different designs or variations in microstrip antenna by changing the substrate material, height, width and dimensions to some amount, produce either wider bandwidths or multiplefrequency operations in a single element. The general microstrip patch antenna design and formulas has been studied. ${ }^{1}$ For $\mathrm{X}$ band applications, some papers have been studied and designed an antenna to analyze how it works well at frequency above $10 \mathrm{GHz}^{2-4}$ An S-shaped patch antenna was created for $\mathrm{x}$ band applications specifically for wireless/microwave applications where two slots are perturbed to the surface current path. ${ }^{3}$ For biomedical applications, spiral shaped patch antenna was introduced to operate at ISM band with good results. ${ }^{5}$ For WLAN, WiFi/WiMAX applications, Inverted dual U slot antenna

${ }^{*}$ Author for correspondence 
introduced to operated in multiband frequency by changing the bridge gap between the dual U slots. ${ }^{6}$ To detect the breast cancer in early stage the author introduced an antenna to resonate at $2.45 \mathrm{GHz}$ and the results are in good agreement with simulated and fabricated antenna. ${ }^{7}$ This author had done the research to wear the antenna into clothing to monitor the human activities such as body temperature, pressure, heartbeat rate etc. ${ }^{8} \mathrm{~A}$ compact wearable antenna with ultra wide band works well in textiles engineering when antenna embedded on clothes. ${ }^{9}$ The body worn antenna has been introduced in this paper with fleece substrate and simulated results shown clearly in this paper. ${ }^{10}$

Among the investigations, triple seven shaped micro strip patch antenna has been introduced and the input power to the antenna given by coaxial cable feed line. The antenna dimensions of $50 \mathrm{~mm}$ x $50 \mathrm{~mm}$ with triple seven shaped antenna designed for $\mathrm{X}$ band radar, military and satellite communication. Many literature surveys have been done, previously proposed designs are bother high in design Complexity, not shrunken, expensive or lagging in multiple band support.

In this paper, a miniaturized single frequency band slotted rectangular patch antenna consist of two rectangular to make single seven shape patch in such a way thrice seven rectangular shaped antenna designed to achieve high return loss factor. By having a proper shapes and dimensions of these triple seven slots are embedded to obtain suitable radiation characteristics and good impedance bandwidth matching. The details of the antenna geometry and its dimensions and some important antenna parameters have been analysed using high frequency synthesis simulator are presented in the following sections.

\section{Antenna Design, Architecture and Optimization}

The geometry and configurations of the proposed triple seven shaped patch antenna are shown in Figure 1. Before designing a triple seven microstrip patch antenna, Firstly a simple patch antenna is designed. Then triple seven patches are embedded on the substrate to resonate at required frequencies. Some design rules and procedures to be followed to select the proper dimensions such as length (L) and Width (W).

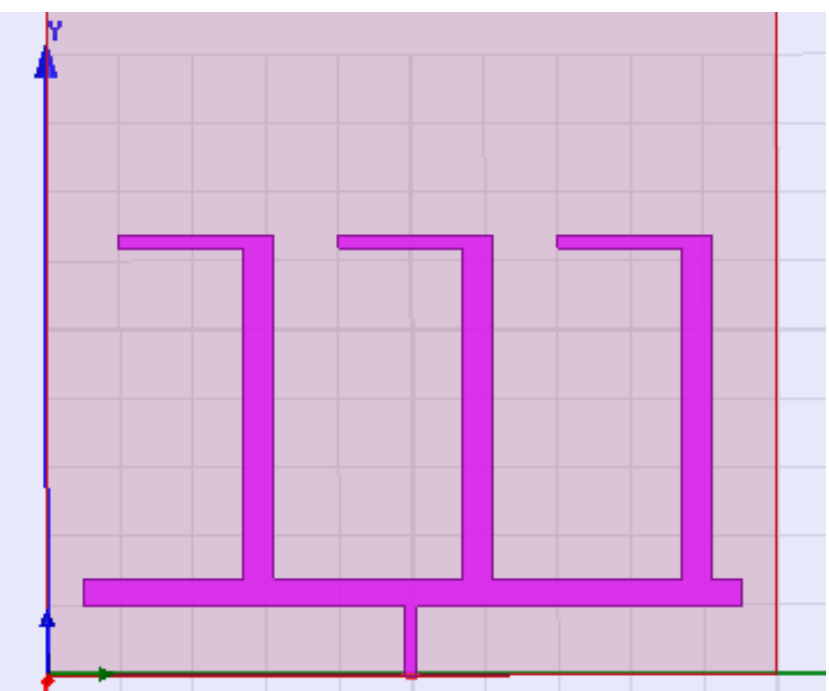

Figure 1. Triple seven shaped UWB Antenna Geometry Top View.

As shown in Figure 2, triple seven patch antenna can reduce the patch size which means the patch area requirement is minimized rather than the conventional rectangular patch antenna. The selection of length $\left(\mathrm{L}_{s}\right)$ and width $\left(\mathrm{W}_{\mathrm{s}}\right)$ of the slots helped us to excite the antenna at $\mathrm{x}$ band frequencies. Generally the length and width of the slots can may change in antenna characteristics such as resonating frequency, Return loss, VSWR, Gain, Directivity etc as already discussed.

The properties of slot length and width on performance of the antenna can be measured when modelling the antenna in terms of inductance, capacitance and its resistance. Here the antenna performance can be simulated using HFSS. The dimensions of the antenna is 50 $\mathrm{mm}$ X $50 \mathrm{~mm}$ with triple seven radiating patch. The slots

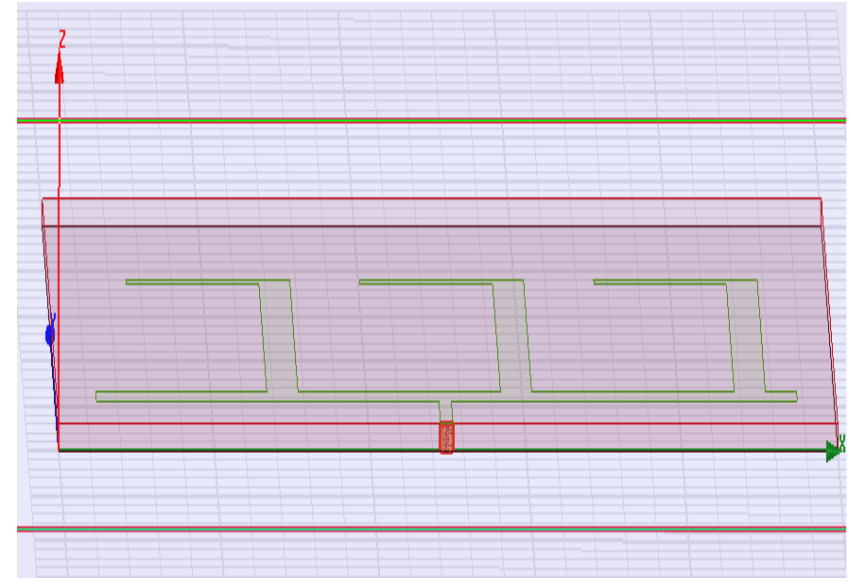

Figure 2. Triple seven shaped UWB Antenna Geometry Side View. 
dimensions $\mathrm{L}_{\mathrm{s}}=25 \mathrm{~mm}$ and $\mathrm{W}_{\mathrm{s}}=0.8 \mathrm{~mm}$ to be calculated to resonate the antenna at $11.4 \mathrm{GHz}$ frequency. The substrate has been taken as Rogers RT/duriod 5880 having relative dielectric constant of 2.20 and loss tangent value is 0.0004 with substrate height is $0.8 \mathrm{~mm}$. The lumped wave port is given. The patch antenna is fed by coaxial cable located at $24.6 \mathrm{~mm}$. The length and width of the feed line is about $0.8 \mathrm{~mm} \mathrm{X} 0.8 \mathrm{~mm}$.

\section{Simulated Results and Discussion}

In Triple seven shaped UWB Antenna for X band Application, the characteristics of the antenna were studied and simulated. For the characteristic studies, the simulation results can be done by HFSS 13.0. To improve the antenna characteristics such as bandwidth, gain, and return loss.

\subsection{Frequency Response}

Figure 3 depicts clearly that the frequency response of the proposed antenna. The feeding point is an important factor while designing micro strip patch antenna. The selection of proper length and width, impedance matching can be achieved at desired bandwidth efficiently. For a good antenna, the return loss value should be lies between $-20 \mathrm{db}$ to $-30 \mathrm{db}$. The behaviour the return loss is nothing but signal should not return back to the originating place. in triple seven shaped patch antenna can have the return loss value as $-29 \mathrm{~dB}$ when the antenna is resonated at $11.4 \mathrm{GHz}$. The designed antenna can be used for X band Applications such as military, radar and satellite communications.

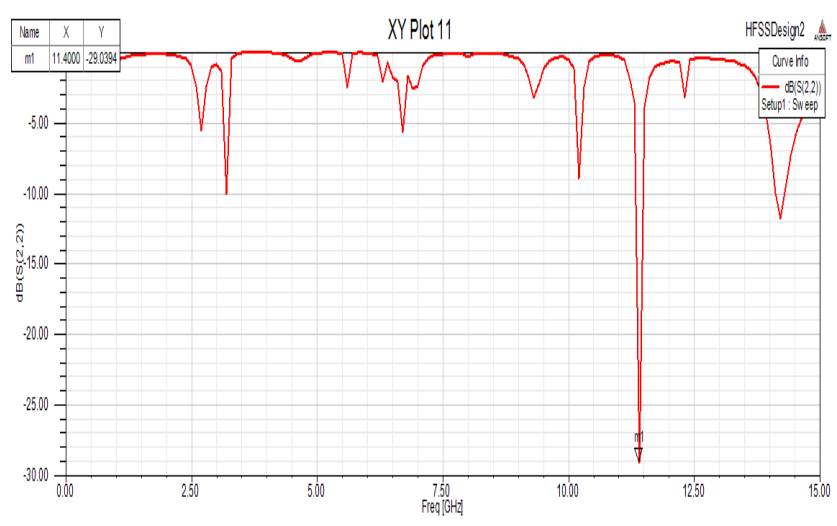

Figure 3. Frequency response of Triple seven shaped UWB Antenna.

\subsection{Gain of the Triple Seven Shaped UWB Antenna}

The Figure 4 depicts the gain of triple seven shaped microstrip patch antenna for $\mathrm{x}$ band applications. The gain versus frequency curve obtained for the proposed antenna is about $2.24 \mathrm{~dB}$.
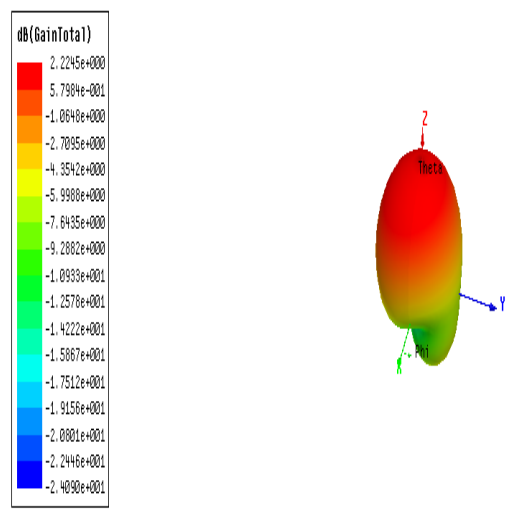

Figure 4. Gain of the Triple seven shaped UWB Antenna.

\subsection{VSWR of the Proposed Antenna}

Figure 5 depicts clearly that the VSWR measurement usually measures that how well the antenna can radiate the input power. The antenna impedance and transmission line impedance should be matched properly. If not, the input power is not received exactly at the receiver side. Therefore, transmission loss occurs which cause the antenna to be an inefficient.

In order to make effective lossless transmission between the transmitter and receiver antenna, the antenna should be matched to the receiver; power is reflected back which cause the reflection coefficient. Often antennas

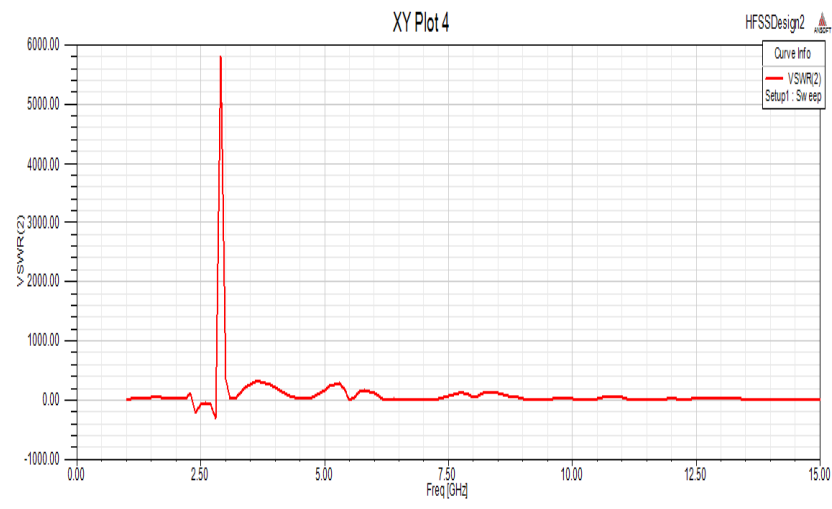

Figure 5. VSWR of Triple seven shaped UWB Antenna. 
must satisfy a bandwidth requirement that is given in terms of VSWR. An antenna might have VSWR less than 3. For the proposed design, the VSWR is about 1 at the frequency 11.4 GHz.

\subsection{Radiation Efficiency of the Triple Seven Shaped UWB Antenna}

Figure 6 depicts clearly that the radiation efficiency of the triple seven shaped microstrip patch antenna has been simulated. The result shows that the designed antenna achieved a maximum radiation efficiency is about $82.83 \%$.
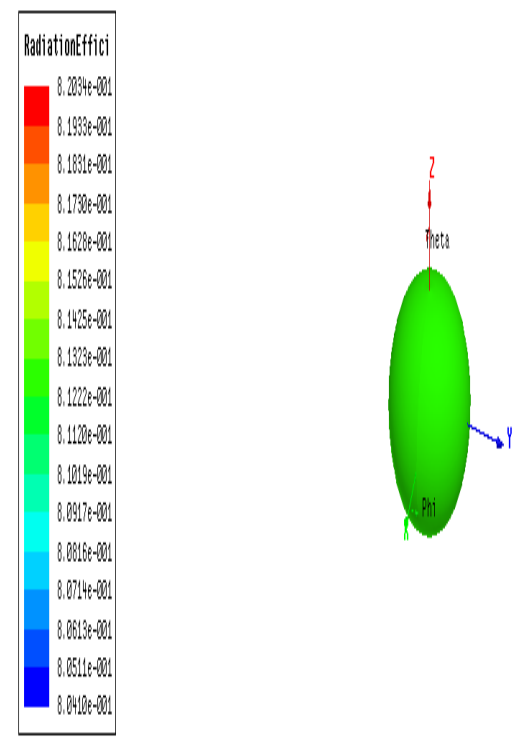

Figure 6. Radiation Efficiency of Triple seven shaped UWB Antenna.

\section{Conclusion}

The proposed triple seven microstrip patch antenna for single band of frequency excited at $11.4 \mathrm{GHz}$. The proposed antenna shows the results with acceptable return loss, VSWR, Radiation Efficiency and gain. The proper changes in length and width gives the better results and therefore, this antenna can be well suited for military, Radar and satellite communication.

\section{References}

1. Balanis CA. Antenna Theory: Analysis and Design. $3^{\text {rd }}$ Edition. Chicester: Wiley; 2012.

2. Coulibaly Y, Denidni TA, Boutayeb H. Broadband microstrip-fed dielectric resonator antenna for X-band applications. IEEE Antennas and Wireless Propagation Letters. 2008; 7:341-5.

3. Aggarwal K, Garg A. A S-shaped patch antenna for X-band wireless/ microwave applications. International Journal of Computing and Corporate Research. 2012; 2(2):1-14.

4. Batra D, Sharma S, Kohli AK. Dual-band dielectric resonator antenna for $\mathrm{C}$ and $\mathrm{X}$ band application. International Journal of Antennas and Propagation. 2012; 2012:1-7.

5. Annakamatchi M, Shalini VK. Design of Spiral Shaped Patch Antenna for Bio-Medical Applications. International Journal of Pure and Applied Mathematics. 2018; 118(11):131-5.

6. Shalini VK, Annakamatchi M. Low Profile- Frequency Reconfigurable Triple Band Antenna for WLAN/ Wi-Fi/ WiMAX Wireless Applications. International Journal of Pure and Applied Mathematics. 2018; 118(8):407-12.

7. Shalini VK. Designing the antenna for ISM band. International Journal of Advanced Research Trends in Engineering and Technology. 2016; 3(7).

8. Annakamatchi M, Priesh P. Design of Compact Wearable Antenna for ISM band. International Journal of Advanced Research in Management, Architecture, Technology and Engineering; 2016. p. 1-4.

9. Ashwal WAMA, Ramli KN. Compact UWB Wearable Antenna with Improved Bandwidth and Low SAR. IEEE International RF and Microwave conference; 2013. p. $90-4$.

10. Annakamatchi M, Keralshalini V, Berlin A. Body Worn Antenna for Telemedicine Applications. In International Journal of Emerging Trends in Science \& Technology. 2017; 3(2). 